\title{
Vigor e produção de sementes de crambe tratadas com fungicida, inseticida e polímero
}

\section{Effects of treating crambe seeds with fungicides, insecticides and a polymer}

\author{
Eduardo José LUDWIG ${ }^{1}$; Ubirajara Russi NUNES ${ }^{4}$; Liliane Marcia MERTZ ${ }^{3}$; \\ Juliano Reis da SILVA'; Silvia Cristina Paslauski NUNES ${ }^{2}$ \\ ${ }^{1}$ Graduando em Agronomia, Universidade Federal de Santa Maria, UFSM, eduludwig@yahoo.com.br; \\ julian_reiss@hotmail.com \\ ${ }^{2}$ Doutoranda em Agronomia, Universidade Federal de Santa Maria, UFSM, spaslauski@yahoo.com.br \\ ${ }^{3}$ Prof. D.Sc., Universidade Federal de Santa Maria, UFSM, lilianemertz@yahoo.com.br \\ ${ }^{4}$ Autor para correspondência; Prof. D.Sc, Universidade Federal de Santa Maria, UFSM; Dept ${ }^{\circ}$ de Fitotecnia, \\ Laboratório Didático e de Pesquisa em Sementes; Avenida Roraima, n. 1000, CEP 97105900, Bairro Camobi, \\ Santa Maria, RS, russinunes@yahoo.com.br
}

Recebido em: 01-02-2013; Aceito em: 02-05-2014

\section{Resumo}

O objetivo do trabalho foi determinar a eficiência do tratamento químico de sementes de crambe com fungicida, inseticida e polímero na qualidade fisiológica e na produção de sementes. Sementes de crambe, cultivar FMS brilhante, foram submetidas aos seguintes tratamentos: T1 = Testemunha; $\mathrm{T} 2$ = Fungicida $(\mathrm{F}) ; \mathrm{T} 3=$ Inseticida $(\mathrm{I}) ; \mathrm{T} 4=$ Polímero $(\mathrm{P}) ; \mathrm{T} 5=\mathrm{F}+\mathrm{I} ; \mathrm{T} 6=\mathrm{F}+\mathrm{I}+\mathrm{P} ; \mathrm{T} 7=\mathrm{F}+\mathrm{P}$, e T8 $=$ I + P. O fungicida utilizado foi o Derosal 500 SC (i.a. Carbendazim), na dose de $3,0 \mathrm{ml} \mathrm{kg}^{-1} \mathrm{de}$ sementes, e inseticida Cruiser $350 \mathrm{FS}$ (i.a. Tiametoxam), na dose de $1,0 \mathrm{~mL} \mathrm{~kg}{ }^{-1}$ de sementes. $O$ polímero utilizado foi o Laborsan (resina sólida), na dose de $0,6 \mathrm{~mL} \mathrm{~kg}^{-1}$ de sementes. Após o tratamento, as sementes foram avaliadas em laboratório pelos testes de germinação, comprimento da raiz e parte aérea e massa seca de plântulas. Em solo, determinaram-se a emergência, 0 comprimento da raiz e da parte aérea e a massa seca de plântulas. Em vasos, foram avaliados a altura das plantas, o número de racemos por planta, o número de frutos por planta, o número de frutos por racemos e a produção de sementes. $O$ tratamento de sementes de crambe com fungicida e/ou inseticida, associado a polímero, afetou o vigor em testes de laboratório e, em condições de solo, não afeta a germinação, a emergência de plântulas e a produção de sementes de crambe.

Palavras-chave adicionais: polimerização; qualidade; revestimento.

\begin{abstract}
The objective of this study was to evaluate the effects of treating crambe cultivar 'FMS brilhante' seeds with a fungicide, an insecticide, and a polymer on their physiological potential and productivity. The treatments were the following : $\mathrm{T} 1=$ control, $\mathrm{T} 2=$ Fungicide $(\mathrm{F}), \mathrm{T} 3=$ Insecticide $(\mathrm{I}), \mathrm{T} 4=$ Polymer $(\mathrm{P}), \mathrm{T} 5=\mathrm{F}+\mathrm{I}, \mathrm{T} 6=\mathrm{F}+\mathrm{I}+\mathrm{P}, \mathrm{T} 7=\mathrm{F}+\mathrm{P}$, and $\mathrm{T} 8=\mathrm{I}+\mathrm{P}$. The fungicide used was Derosal $500 \mathrm{SC}$ (a.i. carbedazim) at the dose of $3.0 \mathrm{~mL} \mathrm{~kg}^{-1}$ of seeds and the insecticide was Cruiser $350 \mathrm{FS}$ (a.i. Tiametoxam) at the dose of $1.0 \mathrm{~mL} \mathrm{~kg}^{-1}$ of seeds. Laborsan (solid resin) was the polymer used at the dose of $0.6 \mathrm{~mL} \mathrm{~kg}^{-1}$ of seeds. After the treatments the seeds were evaluated in the laboratory as to germination, seedling root and aerial part length, and the seedling dry weight. In vases, seedling height, the number of racemes per plant, number of fruits per plant, number of fruits per racemes, and seed production were evaluated. Seed treatment with fungicide and/or insecticide in association with a polymer affected seed vigor as evaluated in laboratory and, in the soil, had no effect on seed germination, seedling emergence and seed production.
\end{abstract}

Additional keywords: polymerization; quality; seed coating.

\section{Introdução}

Crambe abyssinica Hoescht. pertence à família Brassicaceae e é originário da região do Mar Mediterrâneo, sendo extensamente cultivado no México e Estados Unidos. Até recentemente, esta espécie era basicamente destinada à produção de forragem, mas atualmente, devido ao elevado teor de óleo na semente (até $38 \%$ ), vem sendo explorada para extração de biodiesel (NEVES et al., 2007). Além disso, PITOL (2008) destaca que a espécie é útil na indústria de plástico e lubrificante, devido ao alto percentual de ácido erúcico (50 a 60\%), podendo ser viável também na fitorremediação, sendo eficiente na descontaminação de arsênio, cromo e outros metais pesados (ARTUS, 2006). 
O crambe apresenta elevada rusticidade, desenvolvendo-se em condições climáticas antagônicas, suportando geadas no Sul do País e climas quentes e secos típicos do Centro-Oeste (MACHADO et al., 2007), produzindo de forma diferenciada em condições de cultivo com baixa disponibilidade hídrica, onde a maioria das culturas não produziria (CODOLETTI et al., 2012).

Entretanto, apesar da ampla adaptação da cultura, a ocorrência de condições ambientais desfavoráveis na semeadura pode comprometer a germinação e o desempenho de plântulas, prejudicando 0 estabelecimento do estande inicial da cultura. Face ao exposto, a utilização de práticas como o tratamento de sementes com fungicida, inseticida e polímeros pode ser benéfica para a melhoria no estabelecimento das plantas de crambe (TRENTINI et al., 2005).

A peliculização é uma técnica que consiste em revestir ou recobrir as sementes com polímeros, permitindo maior aderência e incorporação dos produtos químicos às sementes, favorecendo a adição de insumos agrícolas, reduzindo os riscos de contaminação ao homem e ao meio ambiente, além de facilitar a diferenciação entre sementes tratadas ou não, sem alterar o tamanho ou a forma. A aplicação de polímeros proporciona uma cobertura durável, permeável à água, com possibilidade de aplicação em sementes de diferentes formas e tamanhos, mantendo as dimensões e os formatos originais, regula o processo germinativo e permite máxima penetração e retenção dos produtos ativos (DINIZ et al., 2006).

Os benefícios da utilização de polímeros nos tratamentos de sementes vêm sendo relatados para diversas espécies, como a soja (LUDWIG et al., 2011), o algodão (LIMA et al., 2006) e o arroz (ARSEGO, 2006). Pesquisas concluíram que a peliculização, associada a fungicida e inseticida, não interfere na germinação e no vigor de sementes (LUDWIG et al., 2011; BAYS, et al., 2007; PEREIRA et al., 2005). Entretanto, para GIMENEZ-SAMPAIO e SAMPAIO (1994), o uso de filmes de revestimento pode aumentar a toxicidade dos produtos químicos aplicados em sementes. PEREIRA et al. (2007), em sementes de soja tratadas com thiram+thiabendazole, constataram que os polímeros AGL 205 ou AGL 202 não afetaram a qualidade fisiológica das sementes e promoveram melhor aderência dos fungicidas, sem alterar os efeitos dos mesmos.

Para a cultura do crambe, as pesquisas relativas ao tratamento químico de sementes ainda são incipientes, não existindo dados de desempenho fisiológico e produtivo de sementes quimicamente tratadas. Diante disso, o objetivo do trabalho foi determinar a eficiência do tratamento com fungicida, inseticida e polímero na qualidade fisiológica e na produção de sementes de crambe.

\section{Material e métodos}

O trabalho foi conduzido no Laboratório de Sementes e em casa de vegetação do Departamento de Fitotecnia, no Câmpus da Universidade Federal de Santa Maria (UFSM)-RS, região climática da Depressão Central.

Sementes de crambe, cultivar FMS Brilhante, produzidas na UFSM, no ano de 2011, e armazenadas com umidade de $10 \%$ em câmara fria e seca $\left(T=15{ }^{\circ} \mathrm{C}\right.$ e UR $\left.=45 \%\right)$, foram submetidas aos seguintes tratamentos: $\mathrm{T} 1=$ Testemunha; $\mathrm{T} 2=$ Fungicida $(\mathrm{F}) ; \mathrm{T} 3=$ Inseticida (I); T4 = Polímero (P); T5 = F + I; T6 = $\mathrm{F}+\mathrm{I}+\mathrm{P} ; \mathrm{T} 7=\mathrm{F}+\mathrm{P}$, e T8 = I + P. O fungicida utilizado foi o Derosal 500 SC (i.a. Carbendazim), na dose de $3,0 \mathrm{~mL} \mathrm{~kg}^{-1}$ de sementes, e inseticida Cruiser 350 FS (i.a. Tiametoxam), na dose de $1,0 \mathrm{~mL} \mathrm{~kg}^{-1}$ de sementes, e polímero Laborsan (resina sólida), na dose de $0,6 \mathrm{~mL} \mathrm{~kg}^{-1}$ de sementes. Após o tratamento, as sementes permaneceram em repouso por $24 \mathrm{~h}$ e, posteriormente, foram avaliadas quanto às características fisiológicas pelos seguintes testes:

- Germinação: foi realizado por meio de semeadura de 200 sementes por tratamento, divididas em quatro repetições de 50 sementes, em caixas plásticas tipo gerbox sobre papel germitest, umedecidos em solução de $\mathrm{KNO}_{3}$ a $0,2 \%$. As caixas foram levadas para a câmara de germinação do tipo B.O.D, sob luz constante e temperatura de $25^{\circ} \mathrm{C}$. As contagens das plântulas foram feitas no $7^{\circ}$ dia (contagem final do teste de germinação). Os resultados foram expressos em percentagem de plântulas normais, conforme BRASIL (2009).

- Comprimento da raiz e parte aérea (hipocótilo): foi realizado ao final do teste de germinação, retirando-se aleatoriamente quatro repetições de dez plântulas cada, determinando-se o comprimento das raízes e da parte aérea com auxílio de régua graduada, obtendo-se o valor médio, expresso em centímetros.

- Massa seca de plântulas: realizado juntamente com o teste de comprimento de plântulas, onde as quatro repetições de 10 plântulas foram acondicionadas em sacos de papel Kraft e levadas à estufa, mantida à temperatura de $70^{\circ} \mathrm{C}$, por 72 horas e, após, pesadas em balança analítica de precisão de $0,001 \mathrm{~g}$, e o resultado, obtido pela média das repetições e expresso em g plântula ${ }^{-1}$.

Outra parte dessas sementes, tratadas conforme descrito acima, foi semeada em solo, em casa de vegetação, a um centímetro de profundidade, espaçadas de $5 \mathrm{~cm}$, com quatro repetições de cinquenta sementes para cada 
tratamento, sendo realizadas irrigações diárias. Aos sete dias após a semeadura, determinou-se a emergência final das plântulas, sendo coletadas quatro repetições de 10 plântulas de cada tratamento, para a determinação do comprimento da raiz e da parte aérea e da massa seca, seguindo o mesmo procedimento descrito anteriormente.

Em casa de vegetação, foram utilizados vasos de PVC preto com volume de cinco litros, tendo como substrato solo classificado como Argissolo Vermelho distrófico arênico (EMBRAPA, 2006), cuja análise química (0$20 \mathrm{~cm}$ ) revelou: $\mathrm{pH}$ em água, 4,8; matéria orgânica: $1,7 \%$; $\mathrm{P}: 2,2 \mathrm{mg} \mathrm{dm}^{-3} ; \mathrm{K}: 24 \mathrm{mg} \mathrm{dm}^{-3}$; Ca: $1,9 \mathrm{cmol}_{\mathrm{c}} \mathrm{dm}^{-3}$; Mg: $0,5 \mathrm{cmol}_{\mathrm{c}} \mathrm{dm}^{-3}$; e saturação por bases de $12,6 \%$. A correção da acidez do solo foi realizada conforme as indicações técnicas para a cultura, tendo por base os resultados da análise do solo, e consistiu na aplicação de $4 \mathrm{t} \mathrm{ha}^{-1}$ de calcário dolomítico (PRNT 100\%). Foram utilizadas seis sementes por vaso, na profundidade de um centímetro, semeadas manualmente no dia 08-05-2012, realizando-se regas diárias e mantendo o solo em capacidade de campo. No momento da emergência dos primórdios foliares (dez dias após a semeadura), numa extensão superior a um centímetro, procedeu-se ao desbaste, deixando-se duas plantas por vaso. Foram aplicados, na semeadura, superfosfato triplo na dose de $400 \mathrm{~kg} \mathrm{ha}^{-1}$; $222 \mathrm{~kg} \mathrm{ha}^{-1}$ de ureia e $133 \mathrm{~kg} \mathrm{ha}^{-1}$ de cloreto de potássio. Em cobertura, vinte dias após a semeadura (DAS), foram aplicados $100 \mathrm{~kg} \mathrm{ha}^{-1}$ de ureia.

Tabela 1 - Germinação, comprimento da radícula, comprimento da parte aérea e massa seca de plântulas de crambe, em laboratório, submetidas a diferentes tratamentos de sementes. Laboratory results of crambe seeds germination, root length, shoot length, and seedling dry weight as influenced by seed treatments.

\begin{tabular}{lcccc}
\hline${ }^{1}$ Tratamentos & $\begin{array}{c}{ }^{2} \text { Germinação } \\
(\%)\end{array}$ & $\begin{array}{c}{ }^{2} \text { Comprimento da }{ }^{2} \text { Comprimento da } \\
\text { radícula } \\
(\mathrm{cm})\end{array}$ & $\begin{array}{c}{ }^{2} \text { Massa seca } \\
\text { parte aérea } \\
\text { de }\end{array}$ & $\begin{array}{c}\mathrm{cm}) \\
\text { plântulas } \\
(\mathrm{g})\end{array}$ \\
\hline T1: Testemunha & $83 \mathrm{a}$ & $2,01 \mathrm{ab}$ & $3,46 \mathrm{a}$ & 0,08 \\
T2: Fungicida (F) & $71 \mathrm{abc}$ & $1,46 \mathrm{bc}$ & $3,56 \mathrm{a}$ & 0,08 \\
T3: Inseticida (I) & $77 \mathrm{ab}$ & $1,40 \mathrm{bc}$ & $3,50 \mathrm{a}$ & 0,07 \\
T4: Polímero (P) & $79 \mathrm{ab}$ & $2,19 \mathrm{a}$ & $3,97 \mathrm{a}$ & 0,08 \\
T5: F+ I & $74 \mathrm{abc}$ & $1,04 \mathrm{c}$ & $3,89 \mathrm{a}$ & 0,07 \\
T6: F + I+P & $68 \mathrm{bc}$ & $0,11 \mathrm{~d}$ & $0,82 \mathrm{~b}$ & 0,05 \\
T7: F+P & $68 \mathrm{bc}$ & $0,17 \mathrm{~d}$ & $0,62 \mathrm{~b}$ & 0,05 \\
T8: $+\mathrm{P}$ & $63 \mathrm{c}$ & $0,24 \mathrm{~d}$ & $1,27 \mathrm{~b}$ & 0,06 \\
\hline CV $(\%)$ & 6,08 & 15,00 & 15,50 & 9,21 \\
\hline
\end{tabular}

\footnotetext{
${ }^{1}$ Tratamento de sementes; ${ }^{2}$ Médias seguidas pela mesma letra na coluna não diferem entre si, pelo teste de Tukey, p>0,05.
}

No experimento conduzido em casa de vegetação, quando se avaliou o desempenho das sementes em solo (Tabela 2), constatou-se que não houve diferença estatística entre os tratamentos para emergência e comprimento da radícula. TRENTINI et al. (2005) constataram, plantas e determinaram-se as seguintes características: altura de plantas (AP), medida com régua na haste principal da planta; número de racemos por planta (NRP), inseridos na haste principal da planta; número de frutos por planta (NFP); número de frutos por racemos (NFR) e produção de sementes (PROD), corrigida para $13 \%$ de umidade.

Foi utilizado o delineamento inteiramente casualizado, com quatro repetições. Os dados foram submetidos à análise de variância, e as comparações entre as médias, realizadas pelo teste de Tukey $(p=5 \%)$.

\section{Resultados e discussão}

$\mathrm{Na}$ Tabela 1, observa-se que, para a variável germinação, o tratamento T1 (testemunha) apresentou valores superiores aos tratamentos T6 $(\mathrm{F}+\mathrm{l}+\mathrm{P})$, T7 $(\mathrm{F}+\mathrm{P})$ e T8 $(\mathrm{I}+\mathrm{P})$, justamente onde foram utilizados inseticida e/ou fungicida associado ao polímero; entretanto, não se diferenciando dos tratamentos T2 $(\mathrm{F})$, T3 (I), T4 $(\mathrm{P})$ e T5 $(\mathrm{F}+\mathrm{l})$. Para o comprimento da radícula $(\mathrm{CR})$, os melhores resultados foram obtidos nos tratamentos $\mathrm{T} 1$ e T4, sendo superiores aos demais. Na variável comprimento da parte aérea (CPA), os tratamentos T1, T2, T3, T4 e T5 superaram os tratamentos T6, T7 e T8, enquanto a massa seca das plântulas não apresentou diferenças entre os tratamentos. Destaca-se que, nos tratamentos onde as sementes foram tratadas com fungicida e/ou inseticida associado ao polímero (T6, T7 e T8), o CR e o CPA foram drasticamente reduzidos 
No comprimento da parte aérea em solo, os tratamentos T1, T2, T3, T4 e T5 não apresentaram diferenças entre si, mas, novamente, os tratamentos T6, T7 e T8 foram inferiores à testemunha. Não houve diferença entre os tratamentos da variável massa seca em solo, com exceção de T5 e T7, que diferiram de T2.

Tabela 2 - Médias de emergência, comprimento da radícula, comprimento da parte aérea e massa seca de plântulas de crambe, em solo, submetidas a diferentes tratamentos de sementes. Soil results of crambe seeds emergence, root length, aerial part length, and seedling dry weight as influenced by seed treatments.

\begin{tabular}{lcccc}
\hline 1'Tratamento & $\begin{array}{c}{ }^{2} \text { Emergência } \\
(\%)\end{array}$ & $\begin{array}{c}{ }^{2} \text { Comprimento da }{ }^{2} \text { Comprimento da } \\
\text { radícula } \\
(\mathrm{cm})\end{array}$ & $\begin{array}{c}{ }^{2} \text { Marte aérea } \\
(\mathrm{cm})\end{array}$ & $\begin{array}{c}\text { Massa seca } \\
(\mathrm{g})\end{array}$ \\
\hline T1: Testemunha & 93 & 2,91 & $3,35 \mathrm{a}$ & $0,09 \mathrm{ab}$ \\
T2: Fungicida $(\mathrm{F})$ & 91 & 2,92 & $3,08 \mathrm{abc}$ & $0,07 \mathrm{~b}$ \\
T3: Inseticida $(\mathrm{I})$ & 94 & 3,02 & $3,18 \mathrm{abc}$ & $0,08 \mathrm{ab}$ \\
T4: Polímero $(\mathrm{P})$ & 96 & 2,49 & $3,33 \mathrm{ab}$ & $0,09 \mathrm{ab}$ \\
T5: $\mathrm{F}+\mathrm{I}$ & 98 & 2,38 & $3,04 \mathrm{abc}$ & $0,1 \mathrm{a}$ \\
T6: $\mathrm{F}+\mathrm{I}+\mathrm{P}$ & 88 & 2,46 & $2,67 \mathrm{c}$ & $0,09 \mathrm{ab}$ \\
T7: $\mathrm{F}+\mathrm{P}$ & 86 & 2,53 & $2,74 \mathrm{bc}$ & $0,1 \mathrm{a}$ \\
T8: I + P & 86 & 2,19 & $2,79 \mathrm{bc}$ & $0,09 \mathrm{ab}$ \\
\hline CV $(\%)$ & 7,80 & 17,00 & 7,79 & 12,43 \\
\hline
\end{tabular}

De acordo com os resultados, evidencia-se que o tratamento de sementes de crambe com polímero, associado ao fungicida e/ou aos inseticidas, provocou efeito fitotóxico nas sementes, principalmente quando avaliado em testes de laboratório. Em condições de solo, esse efeito é diminuído significativamente, possivelmente como resultado da diluição dos produtos pelas irrigações realizadas e pela própria adsorção do produto nas cargas das partículas de solo. Uma alternativa para resolver esse problema seria o ajuste nas doses dos produtos utilizados (fungicida inseticida e polímero). A utilização de doses menores poderia minimizar esse efeito fitotóxico do produto e, dessa forma, melhorar 0 desempenho das sementes de crambe. No gerbox, o polímero pode ter potencializado o efeito do inseticida e do fungicida, e ter sido prejudicial ao crescimento inicial das plântulas, pois, segundo GIMENEZ-SAMPAIO e SAMPAIO (1994), algumas formulações de películas podem prejudicar a germinação das sementes por sua ação de incrementar a toxicidade dos protetores químicos aplicados.

MILTON (1997) observou que o efeito da aplicação de polímero e do tratamento químico sobre a qualidade de sementes de soja não melhorou a eficiência dos fungicidas em sementes com nível médio de germinação e resultou em redução na viabilidade e no vigor das mesmas. Por outro lado, LUDWIG et al. (2011) constataram que a germinação de sementes de soja foi afetada negativamente com o uso do fungicida utilizado, porém a combinação de fungicida e polímero não apresentou este efeito, e a utilização de polímero não afetou o controle de fungos pelo fungicida, indicando que a combinação dos mesmos pode ser utilizada. Em sementes de feijão tratadas com polímeros, associado a fungicidas, PIRES et al. (2004) constataram que a germinação não foi alterada, entretanto a eficiência do controle de patógenos pode ser positiva ou negativa, dependendo do fungicida utilizado e do patógeno presente. De acordo com TRENTINI (2004), a resposta à polimerização depende das características de cada espécie e também dos materiais utilizados no revestimento das sementes.

Quando as sementes foram tratadas apenas com polímero (T4), a germinação, a emergência e o crescimento das plântulas (Tabelas 1 e 2) não apresentaram diferenças em relação a testemunha, confirmando que a qualidade fisiológica das sementes não foi alterada. Estes resultados concordam com EVANGELISTA et al. (2007) e PEREIRA et al. (2009), em que as sementes peliculizadas não prejudicaram a qualidade fisiológica de sementes de soja. TRENTINI et al. (2005) observaram que resultados positivos do uso de películas são obtidos quando as sementes são semeadas em solos em que as condições do ambiente não são favoráveis ao processo de germinação, como solos úmidos e frios, e também aqueles com baixo potencial hídrico. Para NI e BIDDLE (2001), essas películas hidrofílicas ou hidrofóbicas de recobrimento retardam a entrada de água nas sementes, reduzindo os danos de embebição de água em temperaturas frias e aumentam a sobrevivência das sementes. De acordo com EVANGELISTA et al. (2007), o uso de polímeros em sementes de soja auxiliaram na regulação da embebição e, com isso, proporcionaram redução dos danos causados nesse processo, resultando em maior porcentagem de emergência. TAYLOR et al. (2001) constataram que as sementes de feijão 
recobertas apresentaram aumento da germinação, pois o polímero retardou a entrada de água nas primeiras quatro horas, diminuindo assim os danos de embebição.

Para altura de plantas (AP) (Tabela 3), os maiores valores foram obtidos no tratamento 2. Entretanto, houve grande variação para essa característica entre os tratamentos, apresentando valores de $1,14 \mathrm{~m}$ a $1,50 \mathrm{~m}$. Resultados experimentais indicam que a altura média das plantas de crambe varia de $0,60 \mathrm{~m}$ a $0,90 \mathrm{~m}$
(CODOLETTI et al., 2012; SILVA et al., 2012), podendo ultrapassar esses valores, dependendo da época e da densidade de plantio (PEREZ, 1998). Nas plantas com maior altura, também foi obtido o maior número de racemos por planta (NRP), e esta associação é confirmada pela correlação significativa e positiva desta variável com a AP (Tabela 4). Correlação positiva e significativa, e maiores números de frutos por planta (NFP) também foram encontrados em plantas mais altas.

Tabela 3 - Altura de plantas, número de racemos por planta, número frutos por planta, número de frutos por racemos e produção de sementes por planta de crambe, submetidas a diferentes tratamentos de sementes. Crambe plants height, number of racemes per plant, number of fruits per plant, and seed production as influenced by seed treatments.

\begin{tabular}{lccccc}
\hline${ }^{1}$ Tratamentos & $\begin{array}{c}{ }^{2} \text { Altura de } \\
\text { plantas } \\
(\mathrm{cm})\end{array}$ & $\begin{array}{c}{ }^{2} \text { Número de } \\
\text { racemos por } \\
\text { planta }\end{array}$ & $\begin{array}{c}{ }^{2} \text { Número de } \\
\text { frutos por } \\
\text { planta }\end{array}$ & $\begin{array}{c}{ }^{2} \text { Número de } \\
\text { frutos por } \\
\text { racemo }\end{array}$ & $\begin{array}{c}\text { 2 Produção de } \\
\text { sementes por } \\
\text { planta }(\mathrm{g})\end{array}$ \\
\hline T1: Testemunha & $1,18 \mathrm{bc}$ & $18,50 \mathrm{ab}$ & $486,00 \mathrm{ab}$ & $26,27 \mathrm{ab}$ & 5,84 \\
T2: Fungicida $(\mathrm{F})$ & $1,50 \mathrm{a}$ & $20,75 \mathrm{a}$ & $754,25 \mathrm{a}$ & $36,35 \mathrm{a}$ & 6,91 \\
T3: Inseticida $(\mathrm{I})$ & $1,18 \mathrm{bc}$ & $19,25 \mathrm{ab}$ & $380,50 \mathrm{~b}$ & $19,76 \mathrm{~cd}$ & 4,80 \\
T4: Polímero $(\mathrm{P})$ & $1,28 \mathrm{bc}$ & $19,00 \mathrm{ab}$ & $350,00 \mathrm{~b}$ & $18,42 \mathrm{~d}$ & 4,24 \\
T5: $\mathrm{F}+\mathrm{I}$ & $1,20 \mathrm{bc}$ & $18,50 \mathrm{ab}$ & $461,00 \mathrm{~b}$ & $24,91 \mathrm{bcd}$ & 5,28 \\
T6: $\mathrm{F}+\mathrm{I}+\mathrm{P}$ & $1,21 \mathrm{bc}$ & $18,00 \mathrm{ab}$ & $746,00 \mathrm{a}$ & $41,44 \mathrm{a}$ & 5,92 \\
T7: $\mathrm{F}+\mathrm{P}$ & $1,14 \mathrm{c}$ & $13,25 \mathrm{c}$ & $340,25 \mathrm{~b}$ & $25,67 \mathrm{~cd}$ & 4,79 \\
T8: $\mathrm{P}+\mathrm{P}$ & $1,15 \mathrm{c}$ & $15,00 \mathrm{bc}$ & $348,00 \mathrm{~b}$ & $23,20 \mathrm{~cd}$ & 4,70 \\
\hline Média & 1,23 & 17,78 & 483,25 & 27,00 & 5,31 \\
\hline CV $(\%)$ & 8,85 & 10,78 & 22,81 & 25,73 & 26,34 \\
\hline
\end{tabular}

Tabela 4 - Coeficientes de correlação simples ( $r$ ) entre as variáveis analisadas, altura de plantas, número de racemos por planta, número de frutos por planta, número de frutos por racemo e produção de sementes por planta. Simple correlation coefficients ( $r$ ) between plant height, number of racemes per plant, number of fruits per raceme and seed yield per plant.

\begin{tabular}{lccccc}
\hline${ }^{1}$ Variáveis & $\begin{array}{c}{ }^{2} \text { Altura } \\
\text { de } \\
\text { plantas }\end{array}$ & $\begin{array}{c}{ }^{2} \text { Número de } \\
\text { racemos por } \\
\text { planta }\end{array}$ & $\begin{array}{c}\text { Número de } \\
\text { frutos por } \\
\text { planta }\end{array}$ & $\begin{array}{c}{ }^{2} \text { Número de } \\
\text { frutos por } \\
\text { racemos }\end{array}$ & $\begin{array}{c}{ }^{2} \text { Produção de } \\
\text { sementes por } \\
\text { planta }\end{array}$ \\
\hline Altura de plantas & - & $0,43^{* *}$ & $0,46^{* *}$ & 0,25 & $0,50^{* *}$ \\
Número de racemos por planta & - & & 0,20 & $-0,32$ & 0,28 \\
Número de frutos por planta & - & - & - & $0,84^{* *}$ & $0,70^{* *}$ \\
Número de frutos por racemos & - & - & - & - & $0,50^{* *}$ \\
Produção de sementes por planta & - & - & - & - & - \\
\hline
\end{tabular}

${ }^{1}$ Variáveis analisadas; ${ }^{2}$ Significativo a $1 \%$ de probabilidade, pelo teste $t$.

Nos tratamentos 1,2 e 6 , com maior NFP e maiores NRPs (Tabela 4), obteve-se também maior número de frutos por racemo (NFR), também confirmada pela correlação linear positiva e significativa entre NFP e NFR (Tabela 4).

A análise de variância indicou que não houve efeito significativo do uso ou não da película associada a fungicida e/ou inseticida para a produção de sementes (PROD) (Tabela 4), concordando com TRENTINI et al. (2005). Segundo esses autores, em função das condições ideais de temperatura e umidade na semeadura, não há efeito do tratamento das sementes com polímero, condição esta ocorrida no presente experimento, e enfatizam que resultados positivos com polímeros são obtidos quando as condições do ambiente não são favoráveis, como solos com estresse ou saturação hídrica ou solos frios.

Para PROD, obtiveram-se maiores rendimentos nos tratamentos 1,2 e 6 , justamente onde foram detectados os maiores valores de NFR, também confirmados pela correlação significativa entre estas variáveis (Tabela 4). Entretanto, esses tratamentos não foram estatisticamente diferentes dos demais. CARGNELUTTI FILHO et al. (2010) enfatizam que a produtividade de grãos apresentou correlação linear positiva com NFP. Segundo esses autores, as plantas com maior número de frutos são aquelas com maior produtividade de grãos, e tal correlação explica a verdadeira associação existente entre estas variáveis. No presente trabalho, ficou evidente que as plantas 
com maior número de frutos apresentavam também grande número de frutos de pequeno tamanho, havendo efeito compensatório e, dessa forma, não promovendo diferenças significativas entre os tratamentos e na produção final.

\section{Conclusões}

O tratamento de sementes de crambe com fungicida e/ou inseticida associado a polímero afetou o vigor em testes de laboratório.

A aplicação nas sementes de fungicida e/ou inseticida associado ou não a polímero, em condições de solo, não afeta a germinação e a emergência de plântulas de crambe.

A peliculização isolada ou associada a fungicida e/ou inseticida não altera a produção de sementes de crambe.

\section{Referências}

ARSEGO, O.; BAUDET, L; AMARAL, A. S.; HÖLBIG, L.; PESKE, F. Recobrimento de sementes de arroz irrigado com ácido giberélico, fungicidas e polímero. Revista Brasileira de Sementes, Viçosa, MG, v.28, n.2, p.201-206, 2006.

ARTUS, N. N. Arsenic and cadmium phytoextraction potential of crambe compared with Indian mustard. Journal of Plant Nutrition, New York, v.29, p.667-679, 2006.

BAYS, R.; BAUDET, L.; HENNING, A. A.; LUCCA FILHO, O. Recobrimento de sementes de soja com micronutrientes, fungicida e polimero. Revista Brasileira de Sementes, Viçosa, MG, v.29, n.2, p.60-67, 2007.

BRASIL. Ministério da Agricultura, Pecuária e Abastecimento. Regras para análise de sementes. Brasília, DF: Mapa/ACS, 2009. 395p.

CARGNELUTTI FILHO, A.; TOEBE, M.; SILVEIRA, T. R.; CASAROTTO, G.; HAESBAERT, F. M.; LOPES, S. J. Tamanho de amostra e relações lineares de caracteres morfológicos e produtivos de crambe. Ciência Rural, Santa Maria, v.40, n.11, nov, 2010.

COLODETTI, T. V; MARTINS, L. D.; RODRIGUES, W. N.; BRINATE, S. V. B.; TOMAZ, M. A. Crambe: aspectos gerais da produção agrícola. Enciclopédia Biosfera, Centro Científico Conhecer, Goiânia, v.8, n.14, p.258-269, 2012.

DINIZ, K. A.; OLIVEIRA, J. A.; GUIMARÃES, R. M.; CARVALHO, M. L. M.; MACHADO, J. C. Incorporação de microrganismos, aminoácidos, micronutrientes e reguladores de crescimento em sementes de alface pela técnica de peliculização. Revista Brasileira de Sementes, Viçosa, MG, v.28, n.3, p.37-43, 2006.
EMBRAPA. Sistema brasileiro de classificação de solos. Rio de Janeiro: Centro Nacional de Pesquisas de Solos. Embrapa Solos, 2006. 306p.

EVANGELISTA, J. R. E.; OLIVEIRA, J. A.; BOTELHO, F. J. E.; OLIVEIRA, R. M. E.; PEREIRA, C. E. Desempenho de sementes de soja peliculizadas em solo com diferentes teores de água. Ciência e Agrotecnologia, Lavras, v.31, n.4, p.994-999, jul./ago., 2007.

GIMENEZ-SAMPAIO, T.; SAMPAIO, N. V. Recobrimento de sementes. Informativo ABRATES, Londrina, v.4, n.3, p.20-52, dez. 1994.

LIMA, L. B.; SILVA, P. A.; GUIMARÃES, R. M.; OLIVEIRA, J. A. Peliculização e tratamento químico de sementes de algodoeiro. Ciência e Agrotecnologia, Lavras, v.30, p.1091-1098, 2006.

LUDWIG, M. P.; LUCCA FILHO, O. A.; BAUDET, L.; DUTRA, L. M. C.; AVELAR, S. A. G.; CRIZEL, R. L. Qualidade de sementes de soja armazenadas após recobrimento com aminoácido, polímero, fungicida e inseticida. Revista Brasileira de Sementes, Londrina, v.33, n.3 p.395-406, 2011.

MACHADO, M. F.; BRASIL, A. N.; OLIVEIRA, L. S.; NUNES, D. L. Estudo do Crambe (Crambe abyssinica) como fonte de óleo para produção de biodiesel. Itaúna: ENERBIO, Grupo de Pesquisa em Energias Renováveis, UIT, 2007. Disponível em: <http://www.biodiesel.gov.br/docs/congresso2007/ agricultura/39.pdf.> Acesso em: 20 set. 2012.

MILTON, P.Y. Effects of polymer film coating and chemical treatment on quality attributes of soybean seeds. 1997. 95f. Tese (Doutorado) - Mississippi State University, Mississippi State, 1997.

NEVES, M. B.; TRZECIAK, M. B.; VINHOLES, P. S.; TILLMAN, A. C.; VILLELA, F. A. Qualidade fisiológica de sementes de crambe produzidos em Mato Grosso do Sul. In: SIMPÓSIO ESTADUAL DE AGROENERGIA, 2007, Pelotas, RS. Anais... Pelotas: EMBRAPA, 2007. p.97-98.

NI, B. R.; BIDDLE, A. J. Alleviattion of seed imbibitional chilling injury using polymer film coating. In: INTERNATIONAL SYMPOSIUMSEED TREATMENT CHALLENGES AND OPPORTUNITIES, 13. 2001, Brunswick Proceedings... Alton: British Crop Protection Council, 2001. p.73-80.

PEREIRA, C. E.; OLIVEIRA, J. A.; EVANGELISTA, J .R. E.; BOTELHO; F. J. E.; OLIVEIRA, G. E. O; TRENTINI, P. Desempenho de sementes de soja tratadas com fungicidas e peliculizadas durante 0 armazenamento. Ciência e Agrotecnologia, Lavras, v.31, n.3, p.656-665, maio/jun., 2007. 
PEREIRA, C. E.; OlIVEIRA, J. A.; OLIVEIRA, G. E.; ROSA, M. C. M.; NETO, J. C. Tratamento fungicida via peliculização e inoculação de Bradyrhizobium em sementes de soja. Revista Ciência Agronômica, Fortaleza, v.40, n.3, p.433-440, jul-set, 2009.

PEREIRA, C. E.; OLIVEIRA. J. A.; EVANGELISTA, J. R. E. Qualidade fisiológica de sementes de milho tratadas associadas a polímeros durante 0 armazenamento. Ciência e Agrotecnologia, Lavras, v.29, n.6, p.1201-1208, nov./dez., 2005.

PEREZ, S. C. J. G. A. Limites de temperatura e estresse térmico na germinação de sementes de Peltophorium dubium. Revista Brasileira de Sementes, Viçosa, v.20, n.1, p.134-142, 1998.

PIRES, L. L., BRAGANTINI, C.; COSTA, J. L. S. Storage of dry bean seeds coated with polymers and treated with fungicides. Pesquisa Agropecuária Brasileira, Brasília, v.39, n.07, p.709-715, 2004.

PITOL, C. Cultura do crambe. Tecnologia e produção: milho safrinha e culturas de inverno 2008. Fundação MS, 2008. p.85-88.

SILVA, S. D.; ALVES, J. M.; MESQUITA, G. M.; LEANDRO, V. M. Efeito da compactação do solo no desenvolvimento aéreo e radicular do pinhão manso (Jatropha curcas L.) e crambe (Crambe abyssinica Hochst). Global Science and Technology, Rio Verde, v.5, n.2, p.87-97, maio/ago. 2012.
TAYLOR, A. G.; KWIATKOWSKI, J.; BIDDLE, A. J. Polymerfilm coatings decrease water uptake and water vapour movement into seeds and reduce imbibitional chilling injury. In: SEED TREATMENT CHALLENGES AND OPPORTUNITIES PROCEEDINGS OF AN INTERNATIONAL SYMPOSIUM, 2001, Brunswick Proceedings... p.215-220.

TRENTINI, P. Peliculização: preservação da qualidade de sementes de soja e desempenho no estabelecimento da cultura em campo na região de Alto Garças, MT. 2004. $117 f$. Dissertação (Mestrado em Fitotecnia) - Universidade Federal de Lavras, Lavras, 2004.

TRENTINI, P.; VIEIRA, M. G. G. C.; CARVALHO, M. L. M.; OLIVEIRA, J. A.; MACHADO, J. C. Peliculização: desempenho de sementes de soja no estabelecimento da cultura em campo na região de Alto Garças, MT. Ciência e Agrotecnologia, Lavras, v.29, n.1, p.84-92, jan./fev. 2005. 